\title{
Performance of a Cold Formed Steel Pedestrian Bridge under Static and Dynamic Loads
}

\author{
Awaludin, A..$^{*}$, Making, M.Y.M. ${ }^{1}$, Ikhsan, M.N. ${ }^{1}$, and Adiyuano, Y. ${ }^{2}$
}

\begin{abstract}
This paper summarizes new application of cold formed steel (CFS) in bridge constructions where a seven meters long pedestrian bridge was constructed. The bridge has $1.2 \mathrm{~m}$ width, $0.8 \mathrm{~m}$ depth, and is composed of CFS Warren truss and trapezoidal steel deck floor systems. Natural frequency of the bridge considering only dead load application was found as $8.54 \mathrm{~Hz}$ and decreased to $7.08 \mathrm{~Hz}$ when the live load was included. Under static load test, the application of dead load only and both dead and live loads yielded a maximum deflection of 3.53 and $8.1 \mathrm{~mm}$, respectively. Normal walking and running pedestrian loads were carried out created a maximum acceleration equaled to $0.11 \mathrm{~g}$. Lastly, sinusoidal waves application facilitated through a threephase induction motor having self-weight of $24.86 \mathrm{kgf}$ at frequency equal to $8.5 \mathrm{~Hz}$ was performed for one hour resulting no decrease of the natural frequency, thus the bridge can be assumed to experience no noticeable stiffness degradation.
\end{abstract}

Keywords: Pedestrian bridge; cold formed steel; moving pedestrian loads; static and dynamic tests.

\section{Introduction}

Cold formed steel (CFS) has been successfully replaced timber as the main material of roof structures of buildings or housings in Indonesia. This is because of some important advantages offered by CFS, such as: lightness in weight, uniform quality, economy in transportation and handling, fast and easy erection as well as installation, and termite-proof [1]. CFS is a type of steel fabricated under cold forming process including a series of bending process using press brakes. Thus, CFS has a lower ductility ratio and greater yield strength compared to ordinary steel (hot-rolled steel) [2,3]. Addition of corrosion-proof layer during CFS production [4] has substantially minimized construction maintenance activities during service and this is also another important concern for buildings engineers or users.

Light weight construction and high tensile strength are the two most important factors when CFS is intended to be used for bridge constructions, such as truss-deck elements. Pedestrian moving loads in pedestrian bridges are being ideally transformed into axial loads applied at every members of the trussdecks. High axial compression forces can be anticipated by forming built-up section such as box-shaped or I-shaped cross-sections built from two single Cshaped cross-sections connected through self-taping screws or bolts.

${ }^{1}$ Department of Civil and Environmental Engineering, Faculty of Engineering, Universitas Gadjah Mada, Yogyakarta, INDONESIA. ${ }^{2}$ Cahaya Fortuna Sejati Co. ltd. INDONESIA

*Corresponding author; Email: ali.awaludin@ugm.ac.id

Note: Discussion is expected before November, $1^{\text {st }} 2021$, and will be published in the "Civil Engineering Dimension", volume 24, number 1, March 2022

Received 05 August 2021; revised 28 August 2021; accepted 07 September 2021.
Previous studies [5-7] have shown the influence of screw spacing on load bearing capacity of CFS builtup section and recommended suitable screw spacing for design. Composite CFS-Timber system was also proposed to increase axial compression capacity where some timber laminas were attached to the web of I-shaped cross-section (back-to-back two C-shaped sections) through screws [8]. Increase of axial compression capacity however becomes insignificant as member length increases since flange local buckling of CFS governed the failure. This confirms the study of Lu et al. [9] that local buckling cannot be restrained in CFS I-shaped columns when the screws spacing is larger than the local-buckling half-wavelength of the component C-shaped cross-section. However, this may not be the case for closed sections as the screw connections were located at the flanges.

In addition to local buckling potential failure of CFS [10,11], CFS construction designers should also be aware on potential failure of the connection system where self-tapping screws are generally used. Screw connections mostly fail due to inelastic enlargement of CFS sheet around screw holes, leading to large joint deformation before the connections completely fail. In this case, screw spacing governed the final failure of the connections; a closer screw spacing, sheet tear-out would be the final connection failure. A proposal to increase the lateral resistance of CFS connections was reported by Zadanfarrokh \& Bryan, and Wallace $[12,13]$ who used bolts with and without washers instead of screws. From their tests, Wallace [13] found that the lateral resistance of bolted connection without washers is about $75 \%$ of the resistance of bolted connection with washers. Although bolt spacing is a function of sheet thickness, results of connection shear tests composing of two bolts showed that bolt spacing of 2 times of the bolt diameter were 
found to be enough to mobilize the strength of the second bolt [12].

Research reports on application of CFS as roof structures and frame components of low-rise buildings are available in many journals or conference proceedings since few decades ago. However, less research reports have been published on application of CFS in bridge constructions. This study was aimed to evaluate the structural performance of a seven meter long CFS pedestrian bridge under static and dynamic loads. The bridge was designed according to the National Standard SNI 7971:2003 [14] and is described further in the following section.

\section{Research Method}

A pedestrian bridge model composed of 3D Warren truss-deck as shown in Figure 1 was constructed. Warren truss-deck type was adopted following first author's previous report on similar project of pedestrian timber bridge where Howe, Pratt, and Warren truss-deck types were compared [15]. This bridge model had a span length of $7 \mathrm{~m}$, width of $1.2 \mathrm{~m}$, and truss-deck height of $0.8 \mathrm{~m}$. All elements were made of CFS G550 (Lab test results provided by the CFS supplier, $f_{y}=606 \mathrm{MPa} ; f_{u}=629 \mathrm{MPa} ; \varepsilon u=10.7 \%$ ). Structural analysis of the bridge model was carried out according to the standard of pedestrian bridge design published by the Ministry of Public Works of Indonesia [16]. In this design standard, the bridge truss-deck components were designed based on the internal forces due to a uniformly distributed live load of $5 \mathrm{kN} / \mathrm{m}^{2}$ or a concentrated live load of $20 \mathrm{kN}$ at mid span of the bridge. In addition, serviceability limit state requires the maximum deflection of the bridge must be less than the allowable deflection, which is $1 / 200$ of the span length. Structural analysis was performed using SAP2000 [17] assuming that all joints of the truss-deck of the bridge behave as ideal pins.

Design and strength evaluation of the 3D Warren truss-deck members and connections of the bridge model (Figure 2) were conducted based on the National Standard SNI 7971: 2013 [14] and reports $[18,19]$. To anticipate problems of screw loosening as previously mentioned, in fact the bridge model will dominantly undergo moving or dynamic loads thus amplifies problems of screw loosening, several connections were slightly modified by adding one bolt of 8 $\mathrm{mm}$ in diameter into the screw connections. Figure 3 shows the screw and bolt used in the bridge model.

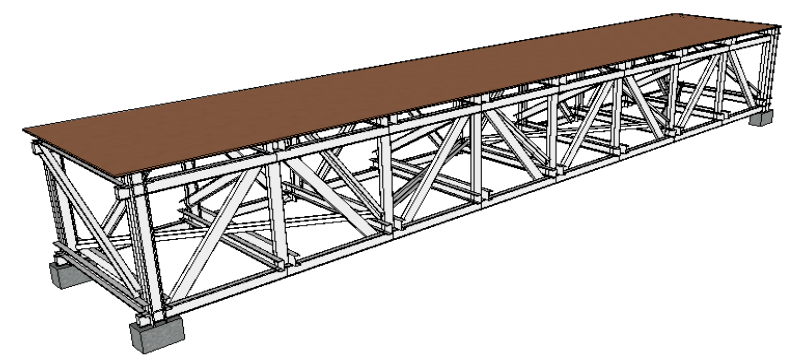

Figure 1. Basic Design of the CFS Pedestrian Bridge Model

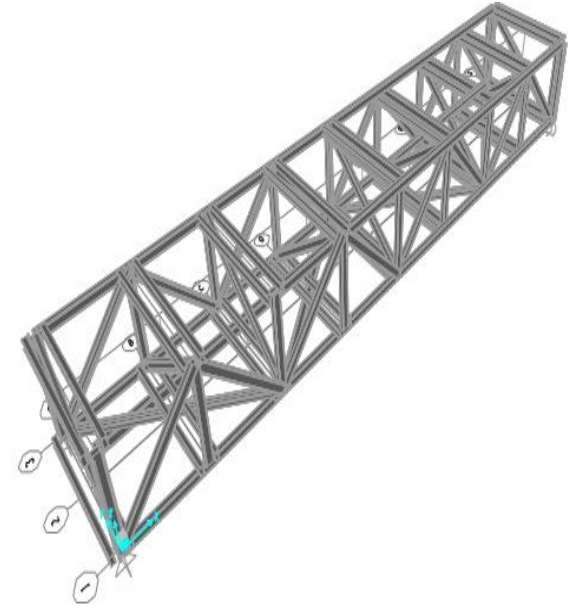

(a)

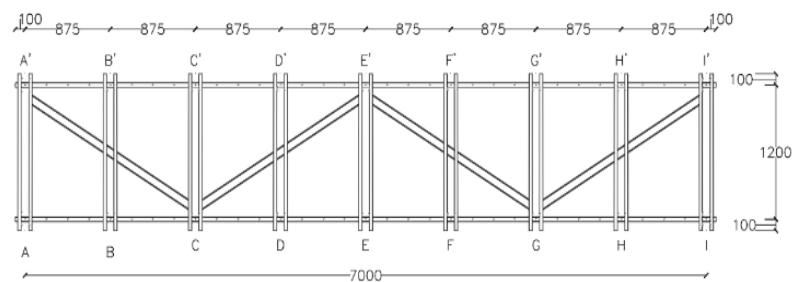

(b)

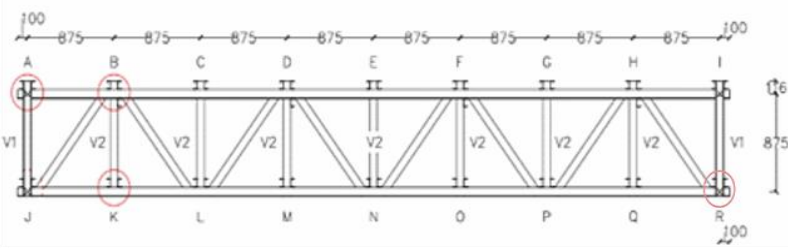

(c)

Figure 2. Model of the Bridge: (a) Model Developed in SAP2000; (b) Bottom View; (c) Side View (unit in mm)

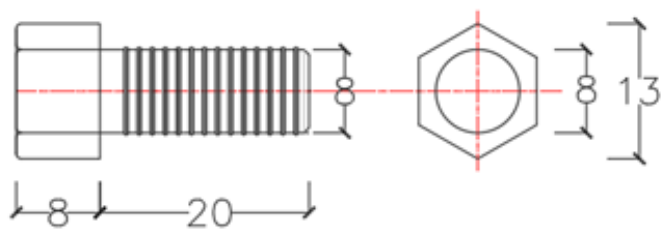

(a)

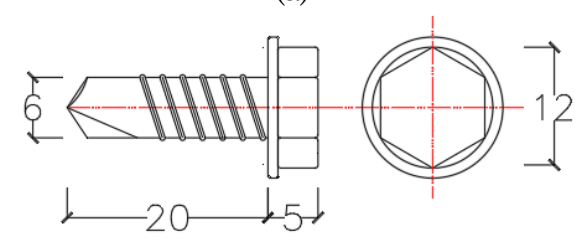

(b)

Figure 3. Bolt (a) and Screw (b) used in the Bridge Model (unit in $\mathrm{mm}$ )

To facilitate application of both static and dynamic loads on top of the bridge during the test, a trapezoidal steel deck (mentioned as steel deck later) of $2 \mathrm{~mm}$ thick covered by $10 \mathrm{~mm}$ thick plywood was placed on the bridge. Reinforced concrete was intentionally not casted on top of the steel deck yet to make it possible for easy transportation of the bridge model (after completion of the test) to its final location, which will be outside of the campus. Assuming concrete slab and 
Table 1. Summary of Axial Force and Used Cross Sections

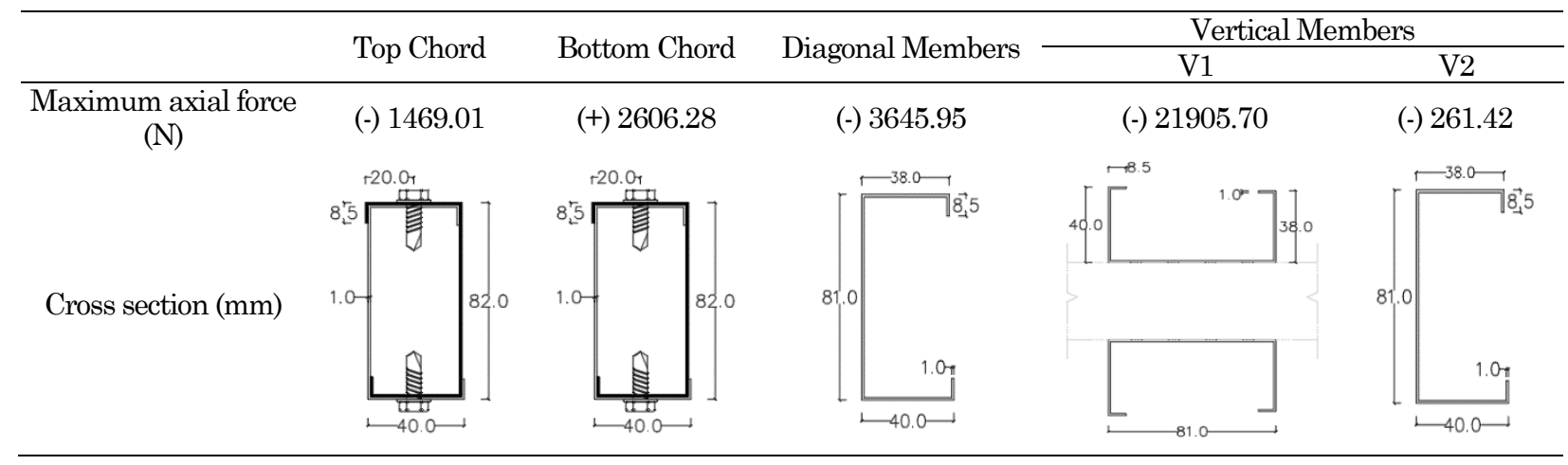

Table 2. Detail of Connections (unit in $\mathrm{mm}$ )

Joint

steel deck of $60 \mathrm{~mm}$ thick, the total weight of this reinforced concrete slab is about $12 \mathrm{kN}$ for an area of slab $1.2 \mathrm{~m}$ by $7 \mathrm{~m}$. The estimated weight of concrete was substituted by 94 cylinders of concrete $(150 \mathrm{~mm}$ diameter and $300 \mathrm{~mm}$ height; average weight is 0.127 $\mathrm{kN}$ ) that are uniformly placed on top of the plywood sheet.

Table 1 summarizes some important facts of results of the analysis and selected CFS sections. Single Cshaped section C81.1 was used in all diagonal members and some vertical members of the trussdeck, while box-shaped section composed of two section of C81.1 was used in top and bottom chord and the outer-most vertical members of the truss-deck. Box-shaped was selected instead of I-shaped section and it is equipped with screws at the interval of 218,8 $\mathrm{mm}$ (not more than four times of depth) [20]. Connections were designed solely based on screws capacity, while at the final stage one bolt of $8 \mathrm{~mm}$ diameter was added into the connections as can be seen in Table 2.

\section{Bridge Test Procedure}

Structural evaluation of the bridge model covered natural frequencies identification, deflection due to uniformly distributed load; dynamic response under moving pedestrian loads and continuous sine waves at frequency close to the natural frequency of the bridge. Identification of natural frequencies was carried out under ambient vibration using two accelerometers ( $2 \mathrm{~g}$ capacity) attached to the bridge at two different locations as shown in Figure 4(a). DW-Soft program was used to transform the recorded dynamic response from time-domain response into frequencydomain response based on Fast Fourier Transform (FFT) technique. As shown in Figure 4 (b), $12 \mathrm{kN}$ of concrete cylinders (equal to $1.43 \mathrm{kN} / \mathrm{m}^{2}$ of distributed load) was placed on the top of the bridge to represent the dead weight of the $60 \mathrm{~mm}$ concrete slab. Furthermore, Figure 4(c) showed the test setup for bridge deflection measurement under uniformly distributed load of about $2 \mathrm{kN} / \mathrm{m}^{2}$ (below design requirement of $5 \mathrm{kN} / \mathrm{m}^{2}$ due to limitation of available 
concrete cylinders) in addition to the existing $12 \mathrm{kN}$ of concrete cylinders. This $2 \mathrm{kN} / \mathrm{m}^{2}$ (or 1.4 ton-force in total) distributed load were applied into two stages (50\% and 100\%), and the bridge deflection at three different locations were measured through three displacement transducers of 50-mm capacity.

Moving pedestrian load was simulated by a group of students performing normal and fast walking. Expected speed [21] of normal and fast walking are, respectively, $1.5 \mathrm{~m} / \mathrm{s}$ and $2.3 \mathrm{~m} / \mathrm{s}$, about twenty students participated in this test. During the test, bridge acceleration at two different locations was continuously recorded and only the $12 \mathrm{kN}$ of concrete cylinders remained on the top of the bridge as can be seen in Figure 4(b).

The last test of this bridge model evaluation was the application of continuous sine wave generated by a three-phase induction motor placed at mid-span of the bridge for one hour. This motor has a self-weight of $24.86 \mathrm{kgf}$ with frequency coverage of $5-20 \mathrm{~Hz}$. A longer duration more than one hour unfortunately was not considered for safety use of the three-phase induction motor. The objective of this test was to examine the potential structural degradation of the bridge model caused by dynamic load especially the screw connection loosening. As test duration was relatively very short, only one hour, frequency of sine wave close to the natural frequency of the bridge model was chosen to have significant deformation amplification, instead of the frequency of normal walking, $1.8-2.0 \mathrm{~Hz}$, [22]. Evaluation of the presence of structural degradation of the bridge was performed by comparing the natural frequencies of the bridge model before and after the application of the one-hour continuous sine wave.

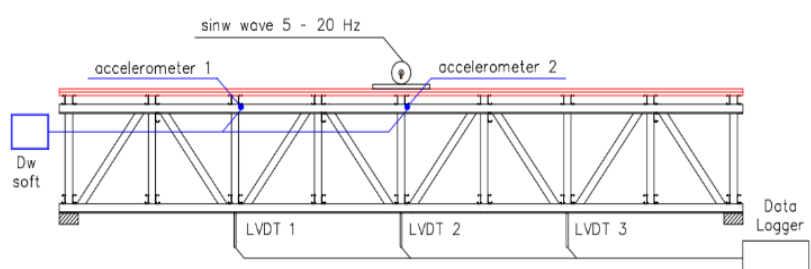

(a)

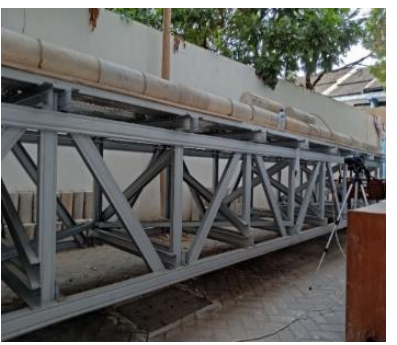

(b)

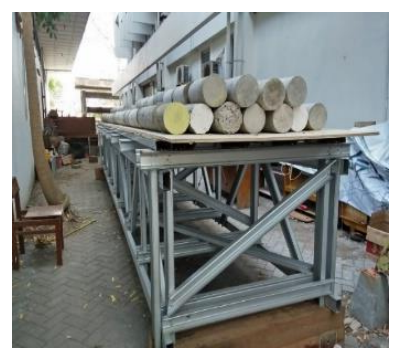

(c)
Figure 4. Bridge Testing: (a) Test Setup; (b) Bridge under DL Loading; (c) Bridge under DL + 100\% LL Loadings.

\section{Bridge Test Results and Discussion}

\section{Natural Frequency}

The first two natural frequencies under vertical vibration were noticed from the acceleration measurement of the bridge as shown in Figure 5, which are 8.54 Hz and 17.3 Hz. Acceleration measurement of the bridge at mid span and quarter span gave an identical result of the natural frequencies. In this Figure 5, the first natural frequency is very dominant compared to others as generally found in many dynamic tests. Bridge acceleration corresponds to the first natural frequency was found equaled to $0.064 \mathrm{~g}$.

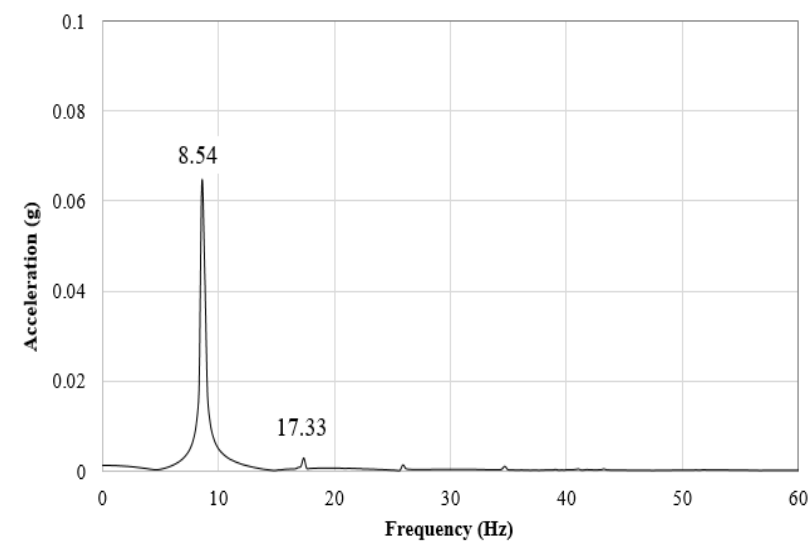

Figure 5. Natural Frequencies of the Bridge Model

\section{Bridge Deflection under Distributed Load}

Figure 6 shows bridge deflection measured through three displacement gauges under four stages of loading: 1) DL (dead loads only); 2) DL + 50\% LL; 3) $\mathrm{DL}+100 \% \mathrm{LL}$; and 4) DL + 0\% LL (unloading of the Live Loads). Maximum deflection of the bridge under loading stage of $\mathrm{DL}+100 \% \mathrm{LL}$ is $8.1 \mathrm{~mm}$, which is still far below the allowable limit L/200 $=7000 / 200=$ $35 \mathrm{~mm}$ [15]. During these four stages of loading, an examination of the first natural frequency of the bridge was also carried out to evaluate the change of natural frequency with respect to increment of total weight of the bridge. The first natural frequency of the bridge was found equal to $8.54 \mathrm{~Hz}, 7.81 \mathrm{~Hz}, 7.08 \mathrm{~Hz}$ and $8.54 \mathrm{~Hz}$, respectively for the four stages of loading.

As indicated in Figure 6, bridge deflection curve in the case of loading stage 4 (Dead Loads plus unloading of the Live Loads) was almost the same with that of the loading stage 1 (Dead loads only), and the first natural frequency was exactly the same. It indicates that the behavior of the bridge model during load test is within elastic response, no in-elastic deformation appears after unloading. 


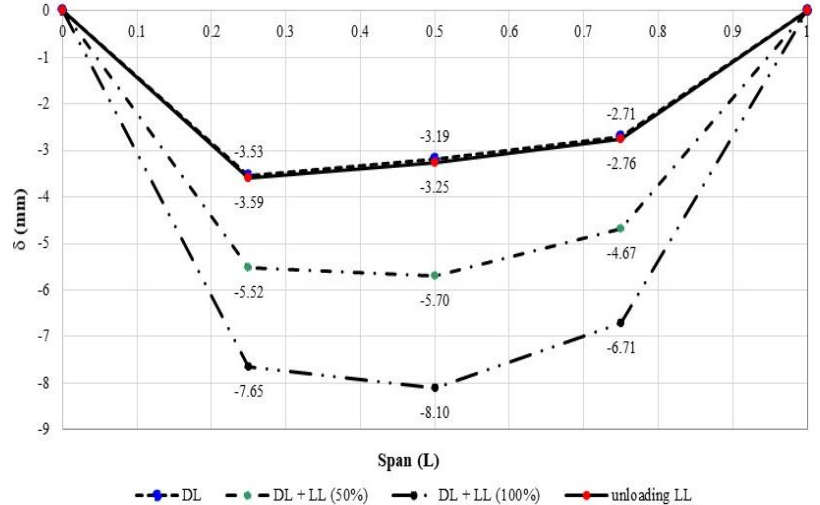

Figure 6. Deflection curve of the bridge model

\section{Bridge Response due to Dynamic Loads}

Figure 7 shows photo of normal walking and jogging on the bridge model. Table 3 summarizes measurement of the dynamic responses of the bridge at midspan and at quarter-span caused by a group of students performing slow walking $(0.58 \mathrm{~m} / \mathrm{s}-0.87 \mathrm{~m} / \mathrm{s})$, normal walking $(1.44 \mathrm{~m} / \mathrm{s}-1.71 \mathrm{~m} / \mathrm{s})$ and jogging $(1.89 \mathrm{~m} / \mathrm{s}-1.94 \mathrm{~m} / \mathrm{s})$. It is clearly indicated in Table 3 that jogging has caused the highest acceleration and deflection of the bridge model compared to the normal and slow walking. Figure 8 shows the bridge acceleration measurement at midspan caused by slow walking, normal walking and jogging where natural frequency of the bridge model in the case of jogging is slightly lower $(8.3 \mathrm{~Hz})$ compared to slow and normal walking $(8.79 \mathrm{~Hz})$.

Figure 9 shows the placement of a three-phase induction motor at mid span of the bridge that generated sine wave at frequency $8.5 \mathrm{~Hz}$ for one hour continuously. During the test, visual monitoring was carried out at certain components of the bridge, especially the connections to examine potential loosening of the screws. After the test, it was confirmed that loosening screws were not exist, local failure of CFS sheets also was not found. This finding was verified by conducting test of natural frequency of the bridge model after the load test where it was found that the first natural frequency of the bridge remained the same, which is $8.54 \mathrm{~Hz}$.

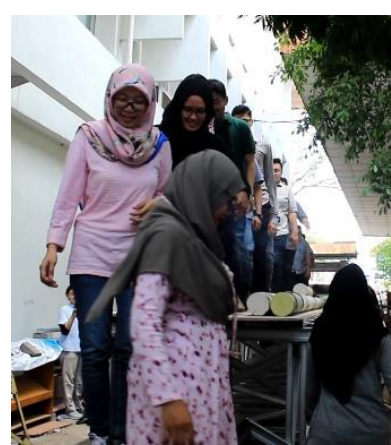

(a)

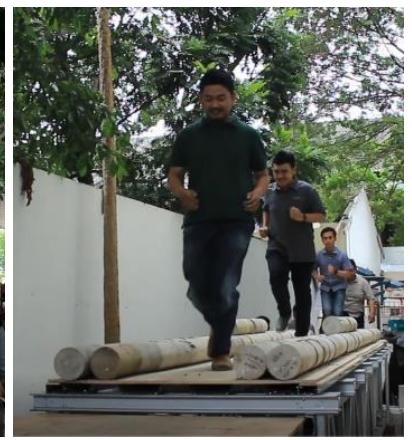

(b)
Figure 7. Normal Walking (a) and Jogging (b) on the Bridge Model

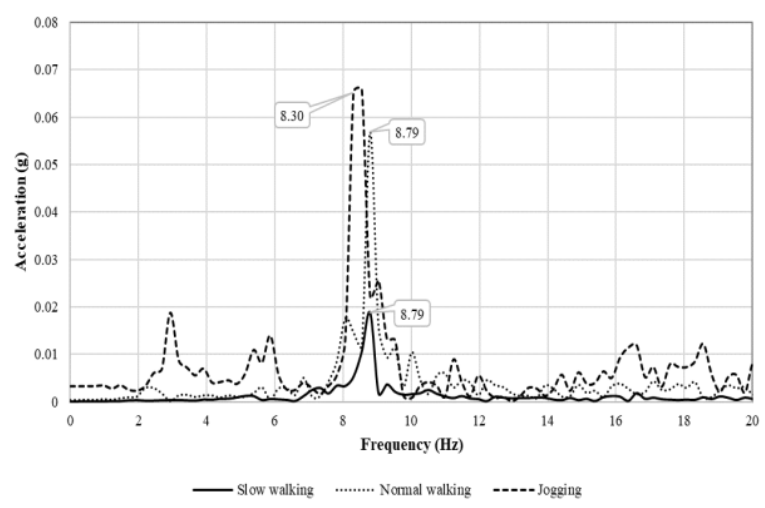

Figure 8. Measured acceleration at mid-span of the bridge

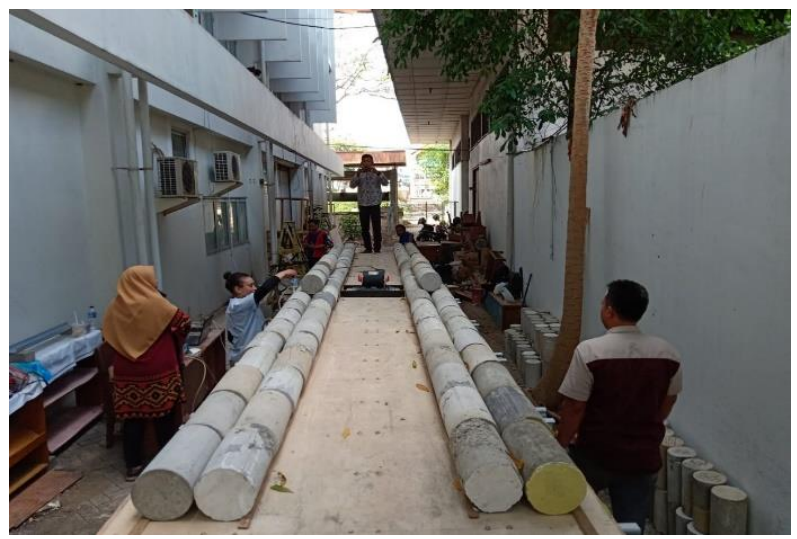

Figure 9. Bridge Test Under Continuous Sine Wave Generated By A Three-phase Induction Motor at Mid Span

Table 3. Measurement of Bridge Acceleration and Deflection During Pedestrian Moving Loads

\begin{tabular}{lcccccccc}
\hline \multirow{2}{*}{ Type of walking } & \multirow{2}{*}{ Test number } & $v$ & \multicolumn{3}{c}{ Mid-span } & \multicolumn{3}{c}{ Quarter-span } \\
\cline { 3 - 9 } & & $(\mathrm{m} / \mathrm{s})$ & $(\mathrm{Hz})$ & $\begin{array}{c}a \\
(\mathrm{~g})\end{array}$ & $\begin{array}{c}\delta \\
(\mathrm{mm})\end{array}$ & $\begin{array}{c}f \\
(\mathrm{~Hz})\end{array}$ & $\begin{array}{c}a \\
(\mathrm{~g})\end{array}$ & $\begin{array}{c}\delta \\
(\mathrm{mm})\end{array}$ \\
\hline \multirow{2}{*}{ Slow walking } & 1 & 0.87 & 8.79 & 0.0188 & 0.380 & 8.79 & 0.0121 & 0.245 \\
& 2 & 0.58 & 8.54 & 0.0198 & 0.424 & 8.54 & 0.0123 & 0.263 \\
\hline \multirow{2}{*}{ Normal walking } & 1 & 1.71 & 8.79 & 0.0569 & 1.150 & 8.79 & 0.0375 & 0.758 \\
& 2 & 1.44 & 8.79 & 0.0149 & 0.301 & 8.79 & 0.0101 & 0.204 \\
\hline \multirow{2}{*}{ Jogging } & 1 & 1.89 & 8.30 & 0.0318 & 0.721 & 8.30 & 0.0235 & 0.533 \\
& 2 & 1.94 & 8.30 & 0.0650 & 1.473 & 8.30 & 0.0469 & 1.063 \\
\hline
\end{tabular}

Note: $v$ is velocity; $f$ is first natural frequency; $a$ is acceleration and $\delta$ is deflection 


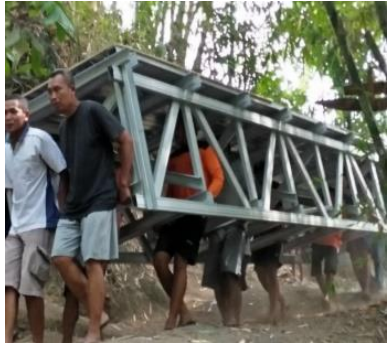

(a)

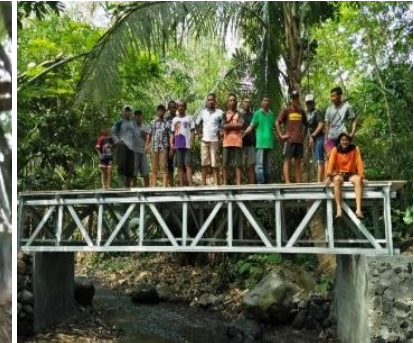

(b)
Figure 10. People carried the bridge model (a) and final location of the bridge model (b)

The bridge was transported to project site at a village nearby the university area for steel deck concreting, railing, and becoming a permanent bridge where crossing people will experience and enjoy the pedestrian bridge made from CFS. Figure 10 shows about fifteen people successfully transported the bridge model near to its final location.

\section{Conclusions}

A seven-meter pedestrian bridge made from Cold Formed Steel constructed introduces new area of the application of CFS, besides its common use as roof structures. The bridge components as well as connections were designed based on a structural model developed by SAP2000 under a uniform distributed live load of $5 \mathrm{kN} / \mathrm{m}^{2}$. Owing to the potential problem of screws loosening at the connections of the truss especially under dynamic loads, bolts were added at the connection systems in addition to screws. Both static and dynamic load tests including moving pedestrian loads performed by a group of students show acceptable bridge performance, the bridge has deflection of $8.1 \mathrm{~mm}$ (less than allowable limit of $\mathrm{L} / 200=35$ $\mathrm{mm}$ ) under a uniform live load of $2 \mathrm{kN} / \mathrm{m}^{2}$ and has first natural frequency of $8.54 \mathrm{~Hz}$.

\section{Acknowledgements}

Authors would like to express their sincere thanks and gratitude to the Department of Civil and Environmental Engineering, Faculty of Engineering of Universitas Gadjah Mada for the partial funding provided. Authors also wish to thank all students who were participating during the bridge test and Ms. Urwatul Wusqo, Ms. Shinta Wardani, and Ms. Sherly Octavia who deal with manuscript layout and template.

\section{References}

1. Alex, J., Iyappan, G.R., and Babu, S.S., Literature Survey on the Fexural Behaviour of Cold Formed Steel Beam Sections, International Journal for Scientific Research \& Development (IJSRD), 4(01), 2016, pp. 748-751.
2. Brockenbrough, R.L. and Merritt, F.S., Structural Steel Designer's Handbook, McGraw-Hill, New York, 1999.

3. Yu, W.W., Cold-Formed Steel Design, Third edition. John Wiley \& Sons, Inc., New York, 2000.

4. Way, A.G., Durability of Light Steel ConstructionED022, Berkshire, The Steel Construction Institute, 2014.

5. Peters, G.K., An Investigation of the Effects of Fastener Spacing in Built-up Cold-formed Steel Compression Members, Nova Scotia, Dalhousie University, 2003.

6. Tang, X. and Ma, H., A Study on Bolted Connection of Built-up I-shaped Member Consisting of Double Thin-Walled Cold-formed Lipped Channels, Proceeding of the $4^{\text {th }}$ International Conference on Advance in Steel Structures, Shanghai, China, June 13-15, 2005, pp. 523-528.

7. Li, Y., Li, Y., Wang, S., and Shen, Z., Ultimate Load-Carrying Capacity of Cold-Formed ThinWalled Columns with Built-Up Box and I-Section Under Axial Compression, Thin-Walled Structures, 79, 2014, pp. 202-217.

8. Awaludin, A., Danastri, A.D., and Supriadi, B., Development of Cold Formed Steel-Timber Composites for Roof Structures: Connection Systems, International Journal of Technology, 7, 2016, pp. 1117-1127.

9. Lu, Y., Zhou, T., Li, W., and Wu, H., Experimental Investigation and a Novel Direct Strength Method for Cold-Formed Built-Up I-Section Columns, Thin-Walled Structures, 112, 2017, pp. 125-139,.

10. Meza, F.J., Becque, J., and Hajirasouliha, I., Experimental Study of Cold-Formed Steel Builtup Column, Thin-Walled Structures, 149, 2020, pp. 1-18.

11. Yu, N., Kim, B., Li, L., Hong, W., and Yuan, W., Distortional Buckling of Perforated Cold-Form Steel Beams subject to Uniformly Distributed Transverse Loads, Thin-Walled Structures, 148, 2020, pp. 1-8.

12. Zadanfarrokh, F. and Bryan, E.R., Testing and Design of Bolted Connections in Cold Formed Steel Sections, Proceeding of the $11^{\text {th }}$ International Specialty Conference on Cold-formed Steel Structures, Missouri, United States, October 20-21, 1992, pp. 625-662.

13. Wallace, J.A., Testing of Bolted Cold-formed Steel Connections in Bearing (with and without Washers). Waterloo, University of Waterloo, 2001.

14. SNI 7971:2013. Indonesian National Standard for Cold-Formed Steel Structures, Badan Standarisasi Nasional, 2013. (In Indonesian).

15. Awaludin, A., Supriadi, B., Nugroho, M.S., Anshari, B., and Ahmad, Z., The First Engineered Pedestrian Bridge using Small Diameter Indonesian Teak Woods: from Design to Project, Proceeding of the 40 th $I A S B E$ Symposium Nantes, Nantes, France, September 19-21, 2018. 
16. Standard of Pedestrian Bridge Design, Ministry of Public Works of Indonesia, 2018. (In Indonesia).

17. Computers and Structures. Inc, Introductory Tutorial for SAP2000, Berkeley, Computers and Structures. Inc, 2009.

18. Komara, I., Wahyuni, E., and Suprobo, P., A Study on Cold-Formed Steel Frame Connection: A Review, IPTEK The Journal for Technology and Science, 28, 2017, pp. 83-89.

19. Ali, B.A., Saad, S., Osman, M.H., and Ahmad, Y., Finite Element Analysis of Cold Formed Steel Connection, International Journal of
Engineering, 5 (2), 2011, pp. 185-193.

20. Wang, L. and Young, B., Behaviour and Design of Cold-Formed Steel Built-Up Section Beams with Different Screw Arrangements, Thin-Walled Structures, 131, 2018, pp. 16-32.

21. Segundinho, A., Dias, A.A., and Carrerira, M.R., Evaluating Vibrations on a Small-Scale Model of a Timber Footbridge, Maderas. Ciencia y tecnología, 13(2), 2011, pp. 143-152.

22. Pachi, A. and Ji, T. Frequency and Velocity of People Walking, The Structural Engineer, 83, 2005, pp. 36-40. 